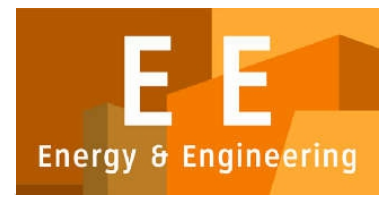

PAPER - OPEN ACCESS

\title{
Karakter Spasial Hunian Vernakular Melayu Deli
}

\author{
Author : Meyga Fitri Handayani, dkk \\ DOI $\quad: 10.32734 /$ ee.v2i1.395 \\ Electronic ISSN : :2654-704X \\ Print ISSN : $2654-7031$
}

Volume 2 Issue 1 - 2019 TALENTA Conference Series: Energy \& Engineering (EE)

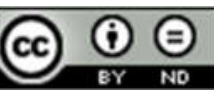

This work is licensed under a Creative Commons Attribution-NoDerivatives 4.0 International License.

Published under licence by TALENTA Publisher, Universitas Sumatera Utara

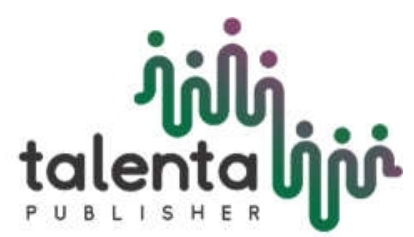




\section{jibli \\ TALENTA Conference Series}

-
Available online at https://talentaconfseries.usu.ac.id

\title{
Karakter Spasial Hunian Vernakular Melayu Deli
}

\author{
Meyga Fitri Handayani ${ }^{\mathrm{a}, \mathrm{b}}$, Mohammed Nawawiy Loebis ${ }^{\mathrm{a}}$, Nurlisa Ginting ${ }^{\mathrm{a}}$, Hilma \\ Tamiami $^{\mathrm{a} *}$
}

${ }^{a}$ Departemen Arsitektur Fakultas Teknik Universitas Sumatera Utara Medan, Indonesia

${ }^{\mathrm{b}}$ Institut Teknologi Medan, Sumatera Utara, Indonesia

*meyga.fitri@itm.ac.id,m.nawawiy@usu.ac.id,nurlisa@usu.ac.id,hilma_32@yahoo.com

\begin{abstract}
Abstrak
Hunian Vernakular dari Malay Deli adalah hunian yang dulu berada di wilayah Kesultanan Melayu Deli. Saat ini, keberadaannya sudah sangat sulit ditemukan dalam kondisi yang baik, beberapa hunian sudah berubah dan rusak. Konsekuensinya, kearifan lokal Sumatera Utara akan hilang. Karakter spasial perlu untuk diidentifikasi untuk mendapatkan tipologi spasial dari tempat tinggal vernakular Melayu Deli. Metode penelitian deskriptif kualitatif. Variabel penelitian adalah aspek spasial seperti orientasi hunian, pola ruang dan hierarki ruang. Pengumpulan data menggunakan metode dokumentasi dan wawancara mendalam. Hasil penelitian menemukan ada 13 jenis karakter spasial vernakular kediaman Melayu Deli.
\end{abstract}

Kata kunci: Perumahan Vernakular, Karakter Spasial, Bahasa Melayu Deli

\begin{abstract}
The Vernacular residence of Malay Deli was a residence that used to be in area of the Deli Malay Sultanate. Nowadays, its existence has been very difficult to find with good conditions, some had changed and damaged. The consequent is the local wisdom of North Sumatera will be lost. It is necessary to identify spatial characters to obtain the spatial typology of vernacular residence vernacular Deli Malay. The research method of qualitative descriptive. The variable research is spatial aspects such as occupancy orientation, patterns of space and hierarchy of space. Data collection using documentation method and deep interview. The result of research found there were 13 type of spatial character vernacular residence Deli Malay.
\end{abstract}

Keywords: Vernacular Residential, Spatial Character, Deli Malay

\section{Pendahuluan}

Di wilayah Pesisir Sumatera Timur dulunya terdapat tiga kesultanan besar yaitu Kesultanan Langkat, Kesultanan Serdang Bedagai dan Kesultanan Deli. Berdasarkan pemetaan bangunan konservasi khususnya arsitektur Melayu di tiga kesultanan ini, disimpulankan kondisi yang sangat mengkhawatirkan akan hilangnya salah satu kearifan lokal di Sumatera Timur berada di wilayah Kesultanan Deli, Penelitian terdahulu berkaitan dengan Arsitektur Melayu Deli lebih banyak difokuskan pada beberapa arsitektur yang kenal seperti Istana Maimoon [1] dan Masjid Raya AlMa'shun [2].

Penelitian ini mengambil obyek studi hunian vernakular Melayu yang dulunya berada di wilayah Kesultanan Deli, dan saat terdiri dari beberapa kecamatan di kota Medan. Rapoport (1969) [3] dalam bukunya House Form and Culture 
membagi arsitektur menjadi dua yaitu grand tradition (tradisi besar) dan folk tradition (tradisi rakyat). Dalam tradisi rakyat Rapoport membaginya lagi menjadi dua yaitu primitif dan vernakular yang terdiri dari vernakular tradisional dan vernakular modern. Penelitian ini menekankan pada arsitektur vernakular tradisional.

Menurut Jambak (2014) [4] arsitektur vernakular adalah arsitektur yang terbentuk dari proses yang berangsur lama dan berulang-ulang sesuai dengan perilaku, kebiasaan, dan kebudayaan di tempat asalnya. Vernakular berasal dari vernacullus yang berarti lokal pribumi. Pembentukan arsitektur berlangsung dengan sangat lama sehingga sikap bentuknya akan mengakar. Lebih lanjut Rapoport (Zubaidi, 2009)[5] menjelaskan beberapa poin tentang karakter arsitektur vernakular sebagai produk yaitu arsitektur vernakular mempunyai tingkat/derajat klasifikasi sesuai budaya dan tempat, model denah, bentuk dan transisi sangat spesifik, mempunyai hubungan antar elemen dan kaidah, penggunaan material serta kualitas bentuk tertentu.

Penelitian ini difokuskan pada hunian vernakular Melayu Deli, mengingat populasi hunian vernakular Melayu Deli semakin sedikit dan sulit ditemui akibat dari moderenisasi, hunian yang tersisa juga sudah banyak mengalami perubahan. Minat masyarakat untuk merawat hunian vernakular ini pun semakin berkurang, karena dari segi fungsionalnya hunian vernakular kurang sesuai dengan aktivitas masyarakat modern. Perubahan jaman, kebutuhan ruang yang meningkat dari penghuni, dan perkembangan kota akan mempengaruhi hilangnya hunian vernakular Melayu Deli, yang diikuti dengan hilangnya identitas kota.

Penelitian ini merupakan upaya pelestarian dari hunian vernakular Melayu Deli dengan melakukan identifikasi karakter spasial hunian vernakular Melayu Deli. Hasil penelitian ini adalah tipologi karakter spasial berkaitan dengan orientasi, pola ruang dan hirarki ruang.

\subsection{Hunian Vernakular Melayu Deli}

Menurut Husny (1976) [6], secara umum karakteristik rumah Melayu dipengaruhi oleh aspek iklim setempat dan syarat agama. Pengaruh iklim dimanifestasikan dalam bentuk rumah berkolong/ panggung dan bertiang tinggi serta ditunjukkan dengan adanya banyak jendela yang ukurannya hampir sama tinggi dengan pintu, banyaknya jendela dan lubang-lubang angin tujuannya untuk memberi udara dan cahaya yang cukup bagi penghuninya. Hal ini terlihat jelas pada hunian vernakular Melayu Deli, bidang lantai berdiri di atas tiang-tiang penyanggah dan bukaanbukaan yang cukup banyak dan lebar.

Penelitian ini akan menganalisis hunian vernakular Melayu baik secara horizontal berkaitan dengan pola dan hirarki ruang, dan pembagian ruang secara vertikal. Seperti pernyataan Zain Z. (2012) [7] kedominanan bentuk yang terdapat pada rumah tradisional Melayu baik secara vertikal maupun horizontal pada elemen pembentuk fasad adalah untuk memberikan perlindungan dan kebebasan bagi anggota keluarga.

\subsection{Karakter Spasial}

Menurut Vidler (Wibowo, 2017) [8] karakteristik bangunan merupakan kajian atau penyelidikan tentang penyatuan elemen-elemen yang membolehkan untuk mencapai pengelompokan organisme arsitektur melalui karakter bangunan. Pengelompokan menghasilkan suatu ringkasan, yang masing-masing dapat ditentukan, dan menyusun ke dalam kelompok-kelompok untuk menentukan data umum dan membolehkan perbandingan-perbandingan pada kasus-kasus tertentu.

Untuk mendapatkan karakter spasial hunian vernakular Melayu Deli ini lebih mudah pengelompokan dilakukan dengan menggunakan tipologi yang disusun dengan tujuan untuk memaparkan karakter paling khas dari tiap kelompok karakter spasial seperti orientasi hunian, pola dan hirarki ruang.

Tipologi dapat dilakukan apabila obyek yang diteliti memiliki kesamaan sifat atau ciri-ciri (Loekito, 1994 dalam Galih, 2012).[9] Untuk itu obyek studi penelitian ini mengambil hunian vernakular Melayu Deli yang dulunya berada di wilayah Kesultanan Deli.

\section{Metode Penelitian}

Penelitian ini menggunakan metode kualitatif deskriptif yaitu mendeskripsikan serta menganalisis data-data yang telah dikumpulkan. Metode pengumpulann data karakter spasial dilakukan dengan observasi dan metode bahan visual yang di lakukan langsung di lapangan. Metode dokumenter dan wawancara mendalam dilakukan untuk mendapatkan sejarah hunian vernakular Melayu Deli. 
Data yang telah dikumpulkan dianalisis untuk mendapatkan karakter spasial hunian vernakular Melayu. Variabel dikhususkan pada aspek spasial yang terdiri dari orientasi hunian, pola ruang dan hirarki ruang.

\section{Hasil dan Pembahasan}

Penelitian ini mengidentifikasi dan menganalsis aspek spasial yaitu orientasi hunian, pola ruang secara vertikal, pola ruang secara horizontal dan hirarki ruang.

\subsection{Karakter Orientasi Hunian Vernakular Melayu Deli}

Lokasi pengamatan diambil dibeberapa kecamatan di kota Medan, Kecamatan Medan Deli, Medan Labuhan, Medan Sunggal, Medan Helvetia, Medan Selayang dan Hamaparan Perak. Dan terdapat 8 (delapan) titik lokasi ditemukannya 25 hunian vernakular Melayu Deli. Dari pengamatan dilapangan orientasi hunian vernakular Melayu Deli sangat beragam, tidak tersusun dengan pola tertentu, tersusun secara acak tidak mengikuti arah mata angin. Orientasi hunian vernakular Melayu Deli mayoritas mengarah ke jalan utama yang ada disekitar tapak dimana hunian berada. (Tabel 1).

Tabel 1. Orientasi Hunian Vernakular Melayu Deli

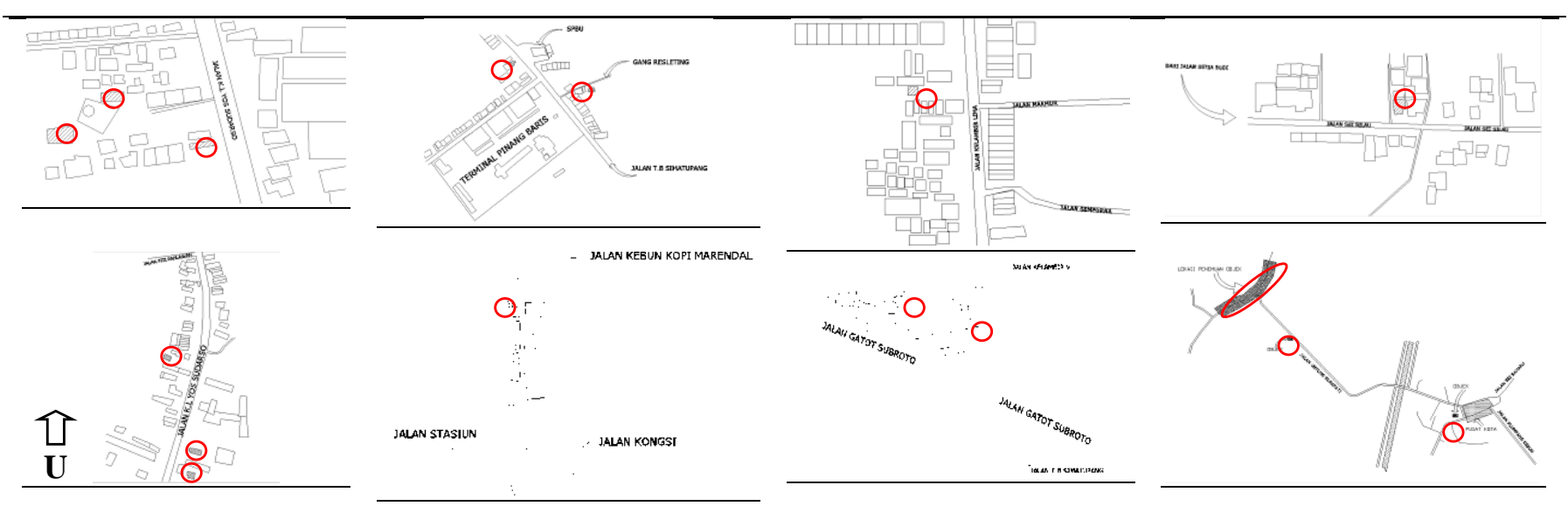

Sumber : Ilustrasi pribadi, 2017

\subsection{Karakter Ruang secara Vertikal}

Pembagian ruang secara umum karena hunian vernakular Melayu Deli merupakan rumah panggung maka pebagian ruang secara vertikal terdiri dari bagian bawah (kaki) yaitu tiang-tiang penyanggah lantai, ruang pada bagian bawah ini disebut dengan kolong. Menurut Husny (1976) [6], masyarakat Melayu dahulunya membangun rumah mereka dengan alasan penyelamatan terhadap bahaya banjir/pasang surut, melindungi dari serangan dan ancaman binatang, menghindari kelembaban dan berfungsi sebagai tempat menyimpan peralatan.

Sedangkan bagian tengah (badan) yaitu bagian yang tersusun oleh beberapa ruang yang sangat jelas fungsi dan hirarkinya. Secara umum menurut Husny (1976)[6] pada bagian tengah ini terdiri dari ruang rumah induk, ruang serambi muka/tamu, ruang dapur/serambi belakang. Untuk bagian atas (kepala) merupakan atap dari hunian. 


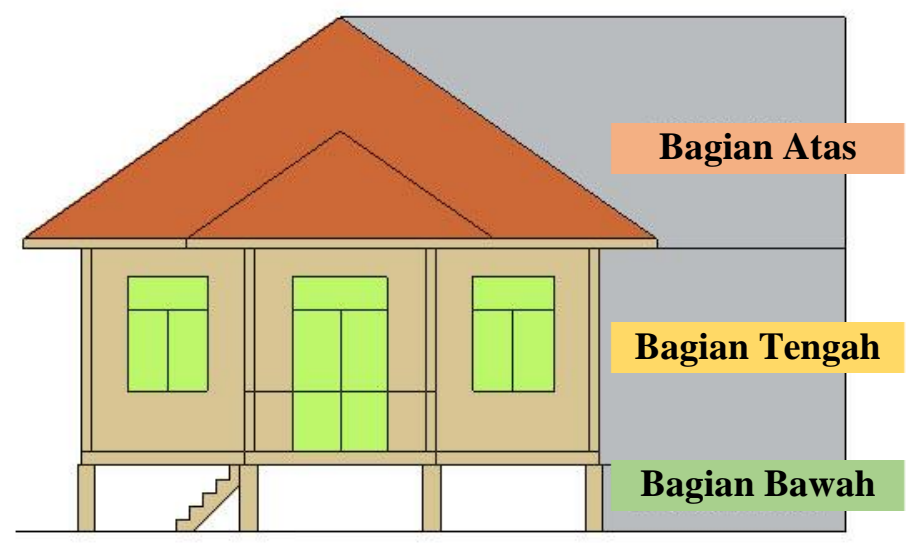

Gambar 1. Pembagian Ruang secara Vertikal (Sumber : Ilustrasi, 2018)

\subsection{Karakter Organisasi Ruang}

Untuk menentukan karakter spasial hunian vernakular Melayu Deli diambil 25 obyek studi, di bawah ini akan disampaikan 5 obyek studi saja untuk mewakilinya, dan diambil berdasarkan usia hunian yang paling lama dibangun. Tabel 2. Obyek Studi

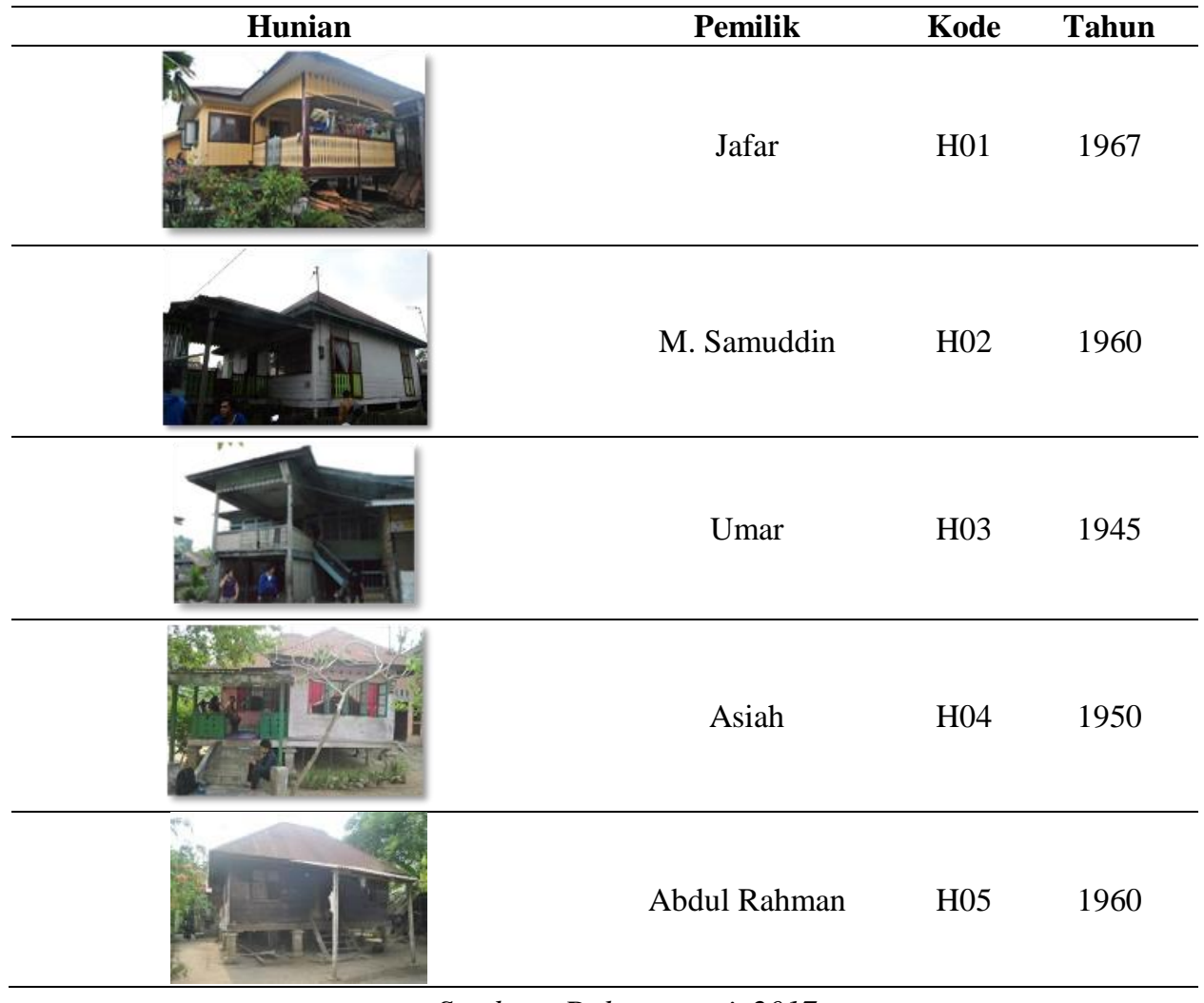

Sumber : Dokumentasi, 2017 


\section{Karakter Pola Ruang H01}

Ruang-ruang tersusun dengan pola linier, dari serambi/teras menuju ruang tamu dan ruang keluarga yang berfungsi juga sebagai ruang makan. Dari ruang tamu berhubungan langsung dengan ruang tidur begitu pula dari ruang keluarga serta ruang makan berhubungan langsung dengan ruang tidur dan halaman belakang rumah.

\section{Karakter Hirarki Ruang H01}

Hirarki ruang terlihat pada susunan ruang pada denah di bawah ini. Tangga menuju serambi berada di samping kiri. Serambi/ teras digunakan untuk tempat menerima tamu (publik), sedangkan ruang tamu, ruang keluarga dan makan difungsikan untuk anggota keluarga (semi privat), dan 2 (dua) kamar tidur bersifat privat.
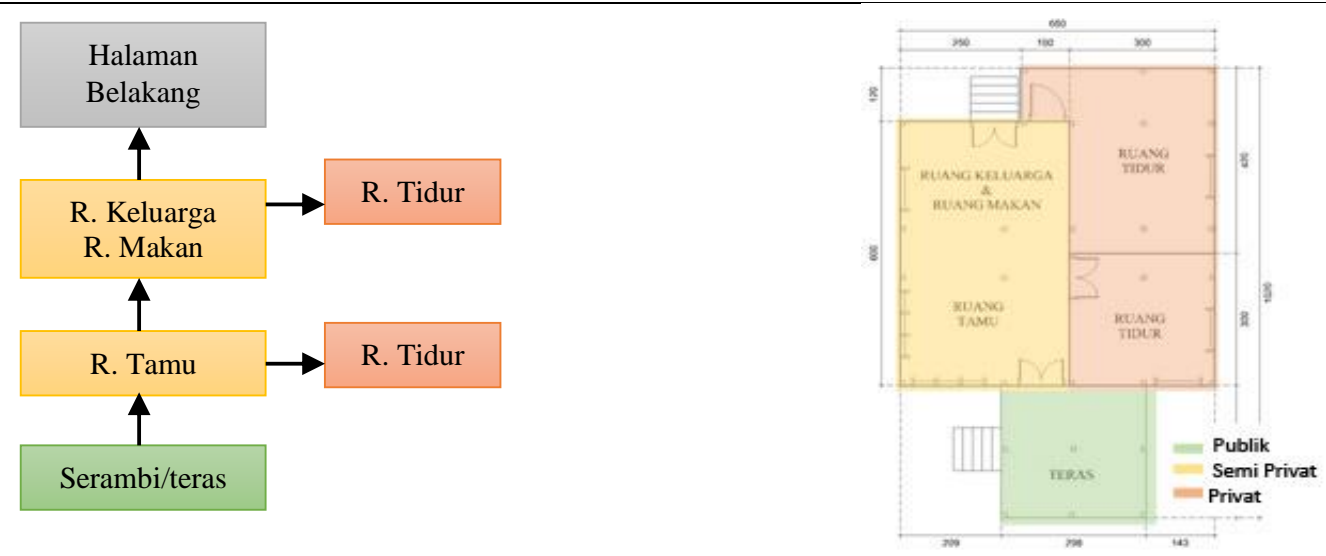

Karakter Pola Ruang H02

Karakter Hirarki Ruang H02

Ruang-ruang tersusun dengan pola linier, dari Hirarki ruang dimulai dari tangga menuju serambi serambi/teras menuju ruang tamu dan ruang keluarga. Terdapat ruang makan yang berdampingan langsung dengan ruang tidur dan menuju halaman belakang rumah.. berada di samping kanan. Serambi/ teras digunakan untuk tempat menerima tamu (publik), sedangkan ruang tamu, ruang keluarga dan makan difungsikan untuk anggota keluarga (semi privat), dan satu kamar tidur dengan privat yang tinggi.

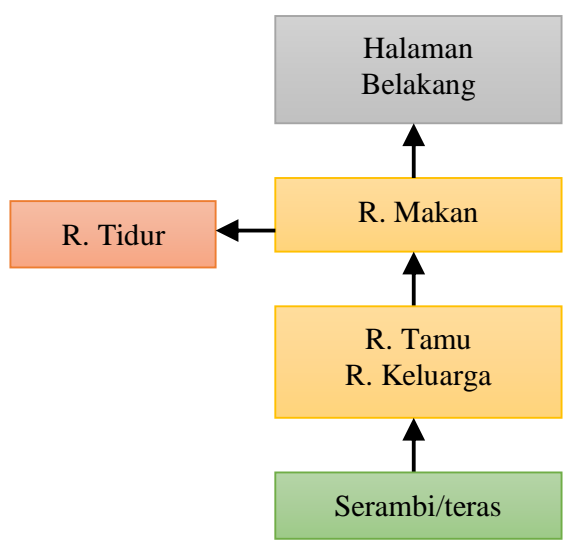

Karakter Pola Ruang H03

Ruang-ruang tersusun dengan pola linier, dari tangga menuju serambi/ teras yang posisinya di depan ruang tamu dan keluarga, Tangga berada disamping kanan serambi. Dari serambi menuju tamu, dan ruang keluarga. Terdapat koridor yang menghubungkan 4 (empat) ruang dengan ruang makan dan dapur. Terdapat tangga menuju kolong rumah, berada di koridor. Dari area ruang makan dan dapur terhubung dengan halaman belakang.

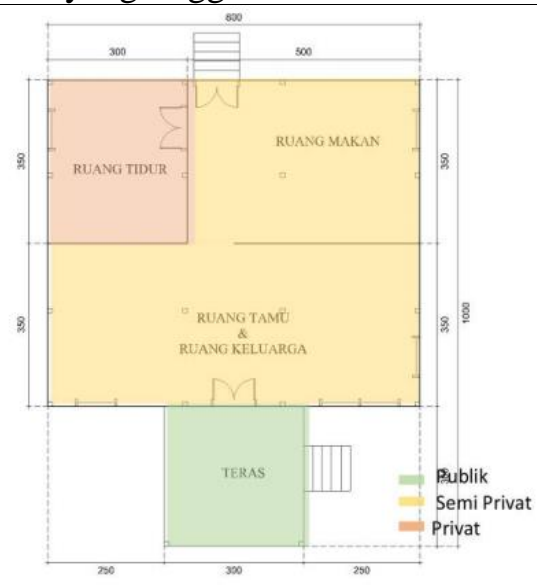

Karakter Hirarki Ruang H03

Hirarki ruang dimulai dari tangga di samping kanan hunian menuju serambi/ teras, serambi/ teras difungsikan sebagai tempat menerima tamu (publik). Ruang Tamu dan ruang keluarga difungsikan untuk menerima tamu keluarga (semi publik). Koridor yang menghubungkan ruang-ruang tidur bersifat semi privat, karena hanya anggota keluarga yang menggunakannya, dan 4 (empat) ruang tidur difungsikan untuk anggota keluarga (privat). Ruang makan dan dapur diletakkan pada bagian belakang bersifat semi privat. 

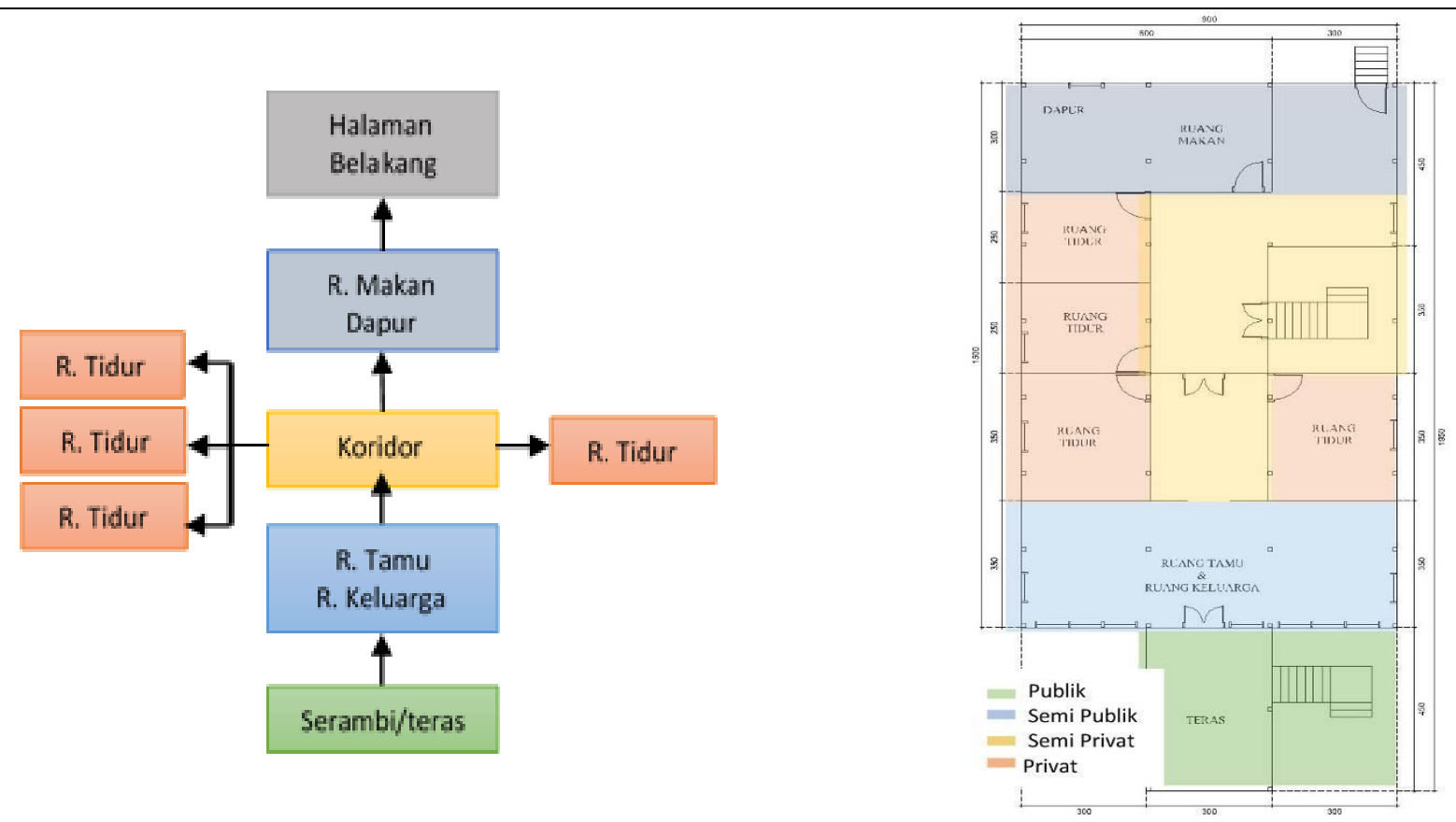

\section{Karakter Pola Ruang H04}

Ruang-ruang tersusun dengan pola linier, dari tangga langsung menuju ruang tamu. Antara ruang tamu dengan ruang keluarga dan ruang makan dihubungkan dengan dapur. Ada 3 ruang tidur, 1 ruang tidur berhubungan dengan ruang tamu, sedangkan 2 ruang tidur berhubungan dengan ruang keluarga dan ruang makan. Dari ruang keluarga dan ruang makan terdapat tangga menuju halaman samping rumah.

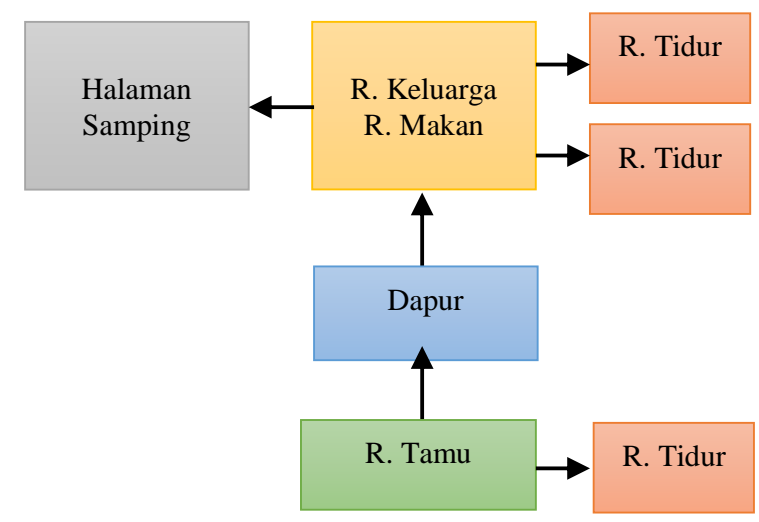

\section{Karakter Hirarki Ruang H04}

Hirarki ruang dimulai dari tangga menuju ruang tamu sebagai tempat menerima tamu (publik), dari ruang tamu menuju dapur yang bersifat semi privat. Selanjutnya terdapat ruang keluarga dan makan difungsikan untuk anggota keluarga (semi privat), dan 3 (tiga) ruang tidur untuk anggota keluarga (privat).

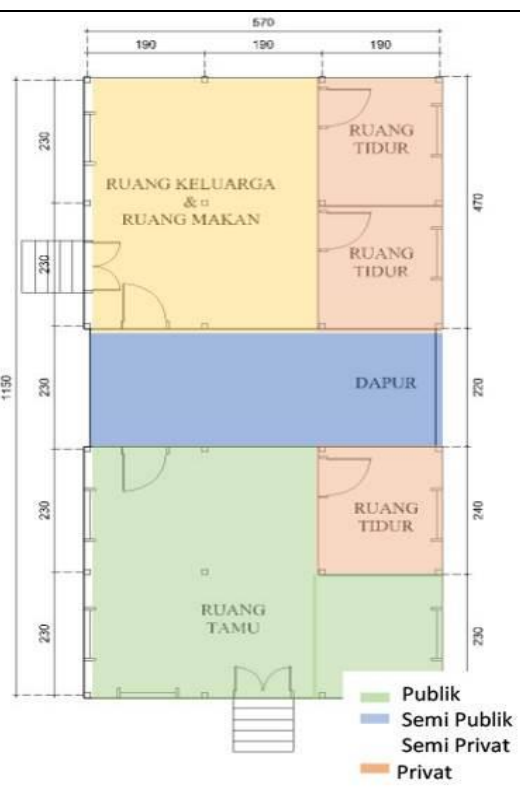


Karakter Pola Ruang H05

Ruang-ruang tersusun dengan pola linier, dari tangga menuju serambi/ teras yang posisinya menjorok ke dalam, berada disamping kiri. Dari serambi menuju tamu, dan berlanjut ke ruang keluarga menyatu dengan ruang makan. Ruang tidur berhubungan langsung dengan keluarga dan ruang makan. Dari ruang keluarga dan ruang makan terdapat tangga menuju halaman belakang rumah.

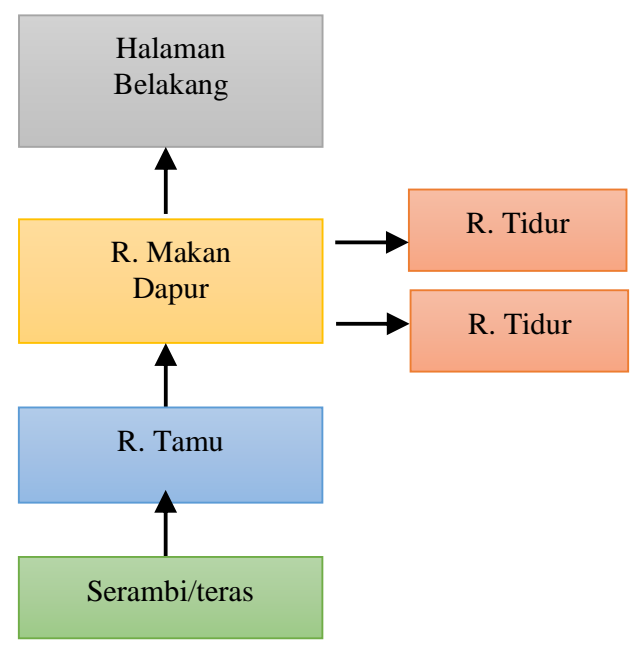

\section{Karakter Hirarki Ruang H05}

Hirarki ruang dimulai dari tangga menuju serambi/ teras yang dibuat menjorok ke dalam, difungsikan sebagai tempat menerima tamu (publik). Ruang Tamu untuk menerima tamu keluarga (semi publik), dari ruang tamu menuju ruang keluarga dan ruang makan (semi privat) difungsikan untuk anggota keluarga (semi privat), dan 2 (dua) ruang tidur difugnsikan untuk anggota keluarga (privat).

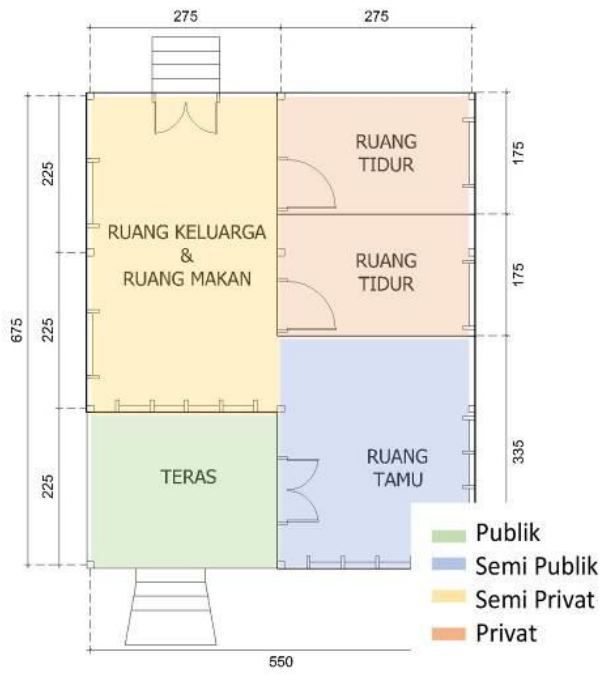

\section{Kesimpulan}

Hasil dari Analisa 25 hunian vernakular Melayu Deli yang dulunya berada di wilayah Kesultanan Deli, didapat 13 karakter spasial dari hunian tersebut. Pengelompokan karakter tersebut ditentukan berdasarkan analisa pola hubungan ruang dan hirarki ruang. Secara umum hirarki ruang pada hunian vernakular Melayu Deli ini sama, baik hunian bertipe kecil maupun besar. Yang lebih banyak membedakan adalah pola susunan ruang dan keberadaan serambi/ teras serta letak dari tangga.

Melalui penelitian ini diharapkan menjadi awal upaya melestarikan kekhasan dari hunian vernakular Melayu Deli. Dan dapat menjadi dokumentasi dan sumber referensi karakter spasial hunian Vernakular Melayu Deli untuk masa yang akan datang.

\section{Referensi}

[1]. Binarwan, R., Chamdani, U. 2014. Istana Maimoon di Kota Medan sebagai Daya Tarik Wisata (DTW). Artikel Kementrian Pariwisata dan Ekonomi Kreatif. pp. 73-85.

[2] Cahya., Elferina D. 2015. Analisis Arsitektur Masjid Raya Al-Ma'shun sebagai Identitas Kota. Dept. Arsitektur. Universitas Sumatera Utara. Skipsi.

[3] Rapoport, A. 1969. House Form and Culture. New Jersey : Prentice Hall.

[4] Jambak, I., Robyana, H, dkk. 2014. Kajian Tradisi Teknologi Membangun Bangunan Masyarakat Baduy Di Kampung Ciboleger, Studi Kasus: Bangunan-Bangunan di Kampung Ciboleger. Jurnal Reka Karsa, Jurnal Online Institut Teknologi Nasional, Teknik Arsitektur Itenas | No.4 | Vol.2, 1-11.

[5] Zubaidi, F. 2009. Arsitektur Kaili sebagai Proses Dan Produk Vernakular. Jurnal "Ruang“ Volume 1 Nomor 1, 27-37.

[6] Husny, M. L. 1976. Bentuk Rumah Tradisi Melayu. Medan.

[7] Zain, Z. 2012. Analisis Bentuk dan Ruang pada Rumah Melayu Tradisional di Kota Sambas Kalimantan Barat. Jurnal NALARs Volume 11 Nomor 1 Januari 2012. Hal : 39-62. 
[8]Wibowo, D. H., Khamdevi, M. 2017. Karakteristik Arsitektur di Desa Mekarwangi, Cisauk-Banten. NALARs Jurnal Arsitektur Volume 16 Nomor 2, 155-160.

[9] Galih W. Pangarsa, Ema Y. Titisari, Abraham M. Ridjal, Ernawati J, 2012. Tipologi Nusantara Green Architecture, Dalam Rangka Konservasi dan Pengembangan Arsitektur Nusantara bagi Kualitas Lingkungan Binaan. Jurnal RUAS, Volume 10 N0 2, 78-94. 